\title{
Interculturalidade e o ensino de alemão como língua estrangeira
}

\section{Cross-culturalism and teaching of German as foreign language}

\author{
Henrique Evaldo Janzen*
}

\begin{abstract}
RESUMO
Este trabalho apresenta, a partir da concepção de linguagem bakthiniana e dos pressupostos da interculturalidade, uma crítica à ausência da mediação cultural/pedagógica em tópicos de unidades temáticas de livros elaborados dentro da abordagem comunicativa; focalizando, primordialmente, o texto ficcional.
\end{abstract}

Palavras-chave: enunciado, cultura, ensino.

\begin{abstract}
This work is a critic, based on Bakhtin's language conception and intercultural remarks, to the lack of cultural/pedagogical mediation in theme units of topics from books elaborated in a communicative approach; this analysis focuses mainly the ficcional text.

Key-words: utterance, culture, teaching.
\end{abstract}

A proposta deste trabalho é analisar - à luz da concepção bakhtiniana de linguagem associada aos pressupostos da interculturalidade - o texto ficcional "Totale Banane über Pukka und Sandale", de Wolfram Siebek, apresentado na lição oito do livro Themen 3, e apontar fragilidades didáticometodológicas, pela ausência de uma mediação cultural e pedagógica, en-

* Mestre em Língua e Literatura Alemã pela USP. Professor de Metodologia e Prática de Ensino de Língua Estrangeira Moderna do DTPEN/UFPR. henrique@educacao.ufpr.br 
frentadas pelo estudante brasileiro na aprendizagem de alemão como língua estrangeira. O presente trabalho é um desdobramento da nossa dissertação, Mediação cultural, abordagem comunicativa e ensino de língua estrangeira: o conceito lingüístico de Bakhtin e os pressupostos da interculturalidade, de modo que nos parece importante retomar alguns elementos da teoria bakhtiniana que norteiam o trabalho, acrescendo a estes novos aspectos, pois o objeto de nossa análise é o texto citado inserido no conjunto de uma unidade temática. É importante ressaltar que, mesmo priorizando a análise do texto ficcional, está ligado a outros itens gêneros discursivos na unidade didática/temática.

A aproximação, neste texto, entre o pensamento bakhtiniano e os pressupostos da interculturalidade centra-se na questão da alteridade, que é elemento fundamental nas duas concepções. O outro é elemento imprescindível e constitutivo de significado, considerando que para Bakhtin a alteridade é condição de identidade. A minimização do papel do outro no ensino de Língua Estrangeira Moderna - LEM - tem gerado dificuldades pedagógicas, limitando o diálogo cultural e consequentemente a aprendizagem, restringindo/impossibilitando, muitas vezes, a ampliação dos horizontes constitutivos de sentido do aluno.

No processo ensino-aprendizagem de uma língua estrangeira, com frequiência, o aluno possui competência linguiística, mas mesmo assim não consegue compreender determinados enunciados por lhe faltar a compreensão do aspecto histórico-cultural da língua/cultura alvo de modo que não existe a compreensão responsiva e ativa do enunciado, mas abstrações que podem ocorrer nas abordagens estruturalista e comunicativa, ressaltando que essas abstrações são de natureza diversas.

Para Bakhtin, o signo é de natureza social e ideológica, diferentemente do conceito de sinal. Neste, o autor aponta o sentido abstrato, sistêmico e monológico e naquele a orientação dialógica (da linguagem). $\mathrm{O}$ signo pode refletir e refratar realidades distintas, estando inserido nos mais diversos contextos. O signo - na linguagem verbal, a palavra - já vem povoado de significados. O enunciado "O muro de Berlim caiu!" pode refletir e refratar realidades distintas, gerando avaliações diversas, pois o foco de observarão/avaliação é distinto. No contexto cultural alemão (intracultural) o enunciado traz consigo valores distintos (depende da orientação axiológica empreendida). Para alguns, pode representar a libertação e a possibilidade de novas perspectivas políticas, econômicas e sociais. Para outros, com outra visão de mundo, poderá significar o fim de uma utopia. "Tudo o que significa encerra, no interior de sua significação, contradições ideológicas" 
(CF. CAStro, 1994, p. 24). Na área pedagógica, no processo ensino-aprendizagem, a compreensão do leitor/estudante brasileiro, ao ler o mesmo enunciado em um livro didático de língua alemã, poderá ser bem diferente. Ele poderá simplesmente reagir dizendo que o muro de sua casa também já caiu, esvaziando o enunciado de seu significado histórico-cultural. O leitor e o seu universo cultural não podem ser dissociados na compreensão dos enunciados.

A partir do exemplo citado, percebemos que, na orientação bakhtiniana de linguagem, o enunciado (a língua) está intrinsecamente ligado à vida, ao contexto no qual está inserido. Para Bakhtin, o discurso verbal é claramente não autosuficiente. Ele depende do contexto extraverbal que lhe dá sustentação e significado. $\mathrm{O}$ autor afirma que o contexto extraverbal (também chamado por Bakhtin de "parte presumida") é produzido em um determinado contexto sociocultural que lhe determina as marcas de representação, as quais organizam o comportamento e as ações de todos os representantes de um grupo; "elas se fundiram, por assim dizer, com os objetos e fenômenos aos quais elas correspondem (...)" (BAKHTIN, 1976, p. 4). ${ }^{1}$

Bakhtin, no mesmo ensaio, explica que o enunciado é de caráter social: "não o que eu amo, penso, mas o que nós ${ }^{2}$ amamos e pensamos" (BAKHTIN, 1976, p. 5). O autor também destaca que só é presumido aquilo que os interlocutores conhecem e avaliam em comum. Este presumido está presente em qualquer enunciado e é sujeito, como visto anteriormente, aos critérios de avaliação ideológica. Todo enunciado é prenhe de resposta, pois a compreensão é ativa e responsiva. O outro está sempre presente; "apenas as relações puramente mecânicas não são dialógicas" (BAKHTIN, 1981, p. 34). Reagimos aos enunciados dos outros - concordando, discordando, achando o tema enfadonho -, dialogamos, mesmo que silenciosamente, com o que foi dito/escrito/visto. Além deste diálogo com o interlocutor, o enunciado dialoga com "ecos e lembranças de outros enunciados" (BAKHTIN 1992, p. 316), com outras visões de mundo, com outras experiências e julgamentos de valor; encontra-se com outras concepções de mundo e outro referencial político-econômico que marcam focos de observação distintos.

1 Este texto foi originalmente publicado em russo, em 1926, sob o título "Slovo v zhizni i slovo v poesie", na revista Zvezda, n. 6, e assinado por V. N. Voloshinov. A tradução para o português, feita por Cristovão Tezza, para uso didático, tomou como base a tradução inglesa ("Discourse in life and discourse in art - corcerning sociological poetics"), publicada em VOLOSHINOV, V. N. Freudism. New York: Academic Press, 1976.

2 Grifo nosso. 
Esta percepção de linguagem calcada na visão axiológica de signo e enunciado perpassa o texto ficcional, as obras literárias. O leitor ou interlocutor não dialoga com entidades abstratas, mas com enunciados concretos a partir de representações próprias. De acordo com Eagleton, "é claro que os leitores não se encontram com os textos no vácuo: todos os leitores estão socialmente e historicamente situados, e a maneira pela qual interpretam as obras literárias será profundamente condicionada por esse fato" (1994, p. 89). ${ }^{3}$

Se o leitor e o seu universo cultural específico não podem ser dissociados da compreensão dos enunciados, parece-nos pertinente refletir sobre o diálogo cultural que os leitores brasileiros estabelecem com textos de língua alemã e as dificuldades provenientes deste diálogo. Dornbusch, ao propor uma nova perspectiva de ensino de Literatura Alemã no Brasil, destaca a dificuldade de compreensão do leitor/estudante/brasileiro no campo da ficção. Segundo a autora: "O elemento estranho deve existir num certo grau, subvertendo o sacralizado, focalizando o já conhecido de forma diferente, produzindo distância crítica. Aquilo que me é completamente estranho no sentido de alheio, não produz empatia, impossibilitando o diálogo" (1997, p. 16). Desta forma, dificulta a formação de sentido e de consciência da alteridade pela ausência de uma mediação cultural-pedagógica mais adequada.

Estabelecer uma relação (dialética) entre a própria cultura e a cultura alheia, no sentido de diálogo cultural, é um dos objetivos básicos da Germanística Intercultural. Um pressuposto (quase) unânime nas mais diversas correntes de investigação da área é o reconhecimento de que cada pessoa, a partir de seu próprio sistema de orientação, partindo de um diferenciado background cultural, procurará interagir com idéias e valores que são utilizados na cultura estranha. Observamos uma tendência ao etnocentrismo, partindo da própria atitude/percepção em relação ao outro que levará a um movimento de rejeição/aproximação.

Em seu texto Estudos literários hoje, Bakhtin aponta para o diálogo entre a cultura própria e a cultura alheia. "A cultura alheia só se revela em sua completude e em sua profundidade ao olhos de outra cultura", pois "formulamos a uma cultura alheia novas perguntas que ela mesma não se formulava. Buscamos nela uma resposta a perguntas nossas, e a cultura alheia nos responde, revelando-nos seus aspectos novos, suas profundida-

3 Entendemos que esta postura mediante as obras literárias pode ser estendida para outros enunciados-gêneros discursivos. 
des novas de sentido" (BAKHTIN, 1997, p. 368). Outros autores, discutindo aspectos da cultura a partir dos estudos da interculturalidade, fazem apontamentos semelhantes e complementares aos de Bakhtin. NITSCHACK (1995, p. 173) destaca que a função do diálogo cultural efetuado pela aproximação a partir do viés cultural-pedagógico é levar a "uma melhor compreensão da outra cultura" e completa destacando também a possibilidade de um distanciamento crítico em relação aos valores considerados óbvios da própria cultura. ZIMMERMAN (1989, p. 20), ao criticar a perspectiva de interculturalidade de Wierlacher, explica que só a perspectiva de "recepção criativa" (Teoria da Recepção) e enriquecedora da outra cultura, na leitura de um texto de língua estrangeira, pode conduzir a uma compreensão falha ou simplesmente à ausência total de significado para o leitor/estudante. Por esta razão, o autor considera fundamental explicar o texto dentro do contexto da língua/cultura alvo. SCHмiDT (1995, p. 342-343), seguindo a mesma orientação, critica a ausência de fundamentação histórica na leitura dos textos e aponta para a falha da hermenêutica intercultural quando esta faz a apologia de leituras aleatórias, que podem levar à subjetivização. BELLER (1987, p. 671) considera que uma reflexão a-histórica provoca falhas na recepção da outra cultura.

A presença de marcas culturais e ideológicas muito específicas da cultura alemã, conjugada à ausência de elementos que indiquem uma mediação pedagógica e cultural, dificulta (ou impede) a compreensão, esvaziando a obra de sentido para o leitor, tendendo para a abstração e não para a formação de sentido para o leitor/estudante. Este gênero do enunciado (obra literária), se não for colocado em perspectiva histórica, contextualizado sob os mais diversos aspectos, poderá gerar avaliações desencontradas, que poderão reforçar preconceitos, clichês e julgamentos descontextualidzados.

Parece-nos pertinente realizar uma breve incursão pela abordagem estruturalista a fim de indicar o caráter de sinalidade no ensino de LEM, que pode ser verificado ainda em alguns encaminhamentos pedagógicos da abordagem comunicativa.

$\mathrm{Na}$ abordagem estruturalista, o enfoque primordial estava centrado em fenômenos lingüísticos de estruturas isoladas e descontextulizadas e na repetição automatizada destas estruturas buscando a internalização da norma (sistematização), não existindo a preocupação com o universo ideológico do aluno (JANZEN 1998, p. 9). Ao fazer a crítica ao estruturalismo (objetivismo abstrato, segundo denominação bakhtiniana), no livro Marxismo e Filosofia da Linguagem, Bakhtin afirma: "A reflexão lingüística de 
caráter formal sistemático é incompatível com uma abordagem histórica e viva da língua". As estruturas são elaboradas e apresentadas como se fossem autônomas, voltadas para o monológico-abstrato.

No exemplo a seguir, o estudante é defrontado com uma situação característica da abordagem fundamentada nessa concepção de linguagem: com o subtítulo de "Wir fragen und antworten", os alunos perguntam e respondem induzidos por uma figura ao lado (voRwärTs ${ }^{4}$ K1, p. 20).

$\mathrm{Na}$ atividade número 1, sugere-se o seguinte procedimento: a) $D u$ fragst: "Bist du krank?" (Você pergunta: Você está doente?) b) Dein Nachbar antwortet: "Ja, ich bin krank". (Teu vizinho responde: Sim, eu estou doente.) $\mathrm{Na}$ atividade número 2, com o mesmo procedimento, a resposta é alterada: a) Du fragst: "Bist du krank"? (Você pergunta: Você está doente?) b) Dein Nachbar antwortet: (Teu vizinho responde): "Nein, ich bin nicht krank. Ich bin gesund" (Não, eu não estou doente. Eu estou com saúde). De forma análoga, o aluno repetirá as estruturas com: "hungrig" (faminto), "traurig"(triste) etc. Fica claro que estas estruturas isoladas e descontextualizadas não comportam um esboço de resposta que ultrapasse o "diálogo" sistêmico. Diálogos construídos artificialmente seguidos por atividades que buscam a automatização de determinadas estruturas - que revestem fenômenos gramaticais - não representam o universo cultural alemão.

Nos livros didáticos elaborados a partir de pressupostos teóricos da abordagem estruturalista, percebemos que há dificuldades para estabelecer diálogo entre a própria cultura e a cultura alheia, pois a teoria privilegia a estrutura da língua em detrimento de seu conteúdo e sua produção efetiva no contexto social. Essa perspectiva teórica favorece a visão de uma Alemanha idealizada nos diversos livros didáticos deste período. Para AMMER (1988, p. 1), que analisa a imagem da Alemanha nos livros didáticos, "os conflitos inexistem. Em seu lugar, todas as relações privadas e sociais são aparentemente permeadas pela harmonia, estabilidade e ordem". Destacamse, também, a hierarquia e a disciplina como valores centrais divulgados nos textos pedagógicos. As personagens são tipificadas: mães, com o papel doméstico; pais como provedores do lar (visão patriarcal); e na atividade profissional, muitas vezes, as personagens não possuem nomes - o médico passa a ser apenas Doktor, representando a impessoalidade. São portanto textos construídos com finalidades pedagógicas, que procuram apresentar uma imagem idealizada da Alemanha (com a presença de inúme-

4 Livro utilizado, em diversas escolas, até o início dos anos 90. 
ros clichês). Linguagem e realidade estão evidentemente dissociadas da vida e da história do aluno, fazendo com que o diálogo cultural fique esvaziado de sentido.

A partir dos pressupostos da abordagem comunicativa, são apresentados textos autênticos, produzidos em situações concretas representativas da vida familiar, social, econômica e política da Alemanha com uma postura crítico-emancipatória. Embora esta concepção de ensino de LEM represente um grande avanço na teoria de ensino, parece-nos que o aluno tem, muitas vezes, dificuldades na aprendizagem pela ausência de uma mediação cultural e pedagógica mais eficiente. Respaldamos a nossa análise na investigação efetuada, em nosso trabalho de mestrado, com professores de LEM (Alemão).

Partindo dessas considerações, passamos a uma breve análise do texto literário "Totale Banane über Pukka und Sandale" inserido em uma unidade do livro didático "THEMEN 3", que assume os pressupostos da abordagem comunicativa. A unidade, focalizando aspectos do passado (tempos verbais), tematiza alguns aspectos relevantes da história da Alemanha dos anos 50-70, utilizando basicamente textos informativos (com predominância do gênero jornalístico). O texto ficcional mencionado focaliza 1968 - a postura revolucionária da época e seus ícones. Nos diálogos e nos comentários presentes no texto, dois jovens tratam com ironia o avô, ridicularizando a sua postura ideológica (Chê como ícone), o vestuário (sandálias), o cabelo ("é verdade que vocês passavam meses sem visitar um salão?") e os slogans (da época) gritados nas ruas etc. No final do texto, o avô e um amigo comentam - com ironia - o desejo dos jovens de hoje: "todos querem ser como Boris Becker".

Não fica claro o que se espera do leitor com este texto do gênero literário inserido no final da unidade. A imprecisão estabelece-se tanto no aspecto didático-metodológico quanto na formação de sentido para o leitor. A escolha de um texto literário que discute uma situação do passado indica mais um reforço estrutural de utilização de tempos verbais do passado do que a inserção do texto ficcional como gênero de discurso (literário) e como enriquecimento temático e intercultural. Convém apontar a extrema heterogeneidade dos gêneros do discurso destacada por Bakhtin, considerando que "cada esfera de utilização da língua elabora seus tipos relativamente estáveis de enunciados (...)" (1997, p. 279). O autor faz distinção entre o gênero de discurso primário (simples) e secundário (complexo). Segundo o autor, "os gêneros secundários (no nosso trabalho, o texto literário), absorvem e transmutam os gêneros primários. Os gêneros primári- 
os, ao se transformarem dentro daqueles, adquirem uma característica particular". Corroboram esta concepção HINDERER (1987, p. 281), também apontando que os textos literários possuem sistemas de representação próprios e podem estar dialogando com outros textos e contextos, e SEVCENKO (1999, p. 20), que, ao analisar o entrecruzamento história e literatura, destaca que "a literatura se preocupa com aquilo que poderia ou deveria ser a ordem das coisas, com as possibilidades do ato criativo, mais do que com o seu estado real", estabelecendo, portanto, uma relação mimética com o texto.

O efeito sobre o leitor pode ser de distanciamento/estranhamento tanto na esfera intracultural quanto intercultural: no texto citado, o leitor, mesmo tendo o domínio da língua estrangeira, pode sentir dificuldades com as marcas do gênero literário, pois não existem, por parte do autorteam, indicações referentes a esse gênero, gerando um possível estranhamento de ordem estética. No âmbito da interculturalidade, destaca-se o provável desconhecimento (do leitor/estudante) do contexto sociocultural (e seus desdobramentos) no qual o texto está inserido.

Embora os textos informativos (e um de opinião) retomem 1968, esta retomada é superficial de modo que a maioria dos alunos provavelmente não compreenderá as marcas socioculturais específicas da cultura alemã. Falta-lhe o contexto extraverbal que dá sustentação e significado ao discurso verbal: as referências históricas à guerra fria, ao espírito autoritário nas universidades, ao famoso Wohlstand (bem estar). Provavelmente os alunos terão dificuldades de compreender a ironia dispensada ao bom moço Boris Becker como ícone da juventude. Além disto, o autorteam do livro didático não oferece ao leitor qualquer informação sobre o autor e a situação da produção do texto: se a temática do texto é recorrente no autor, com quem e com quais outros textos ou situações o autor poderia estar dialogando (o autor pode estar, por exemplo, apenas respondendo a um outro texto literário). Quem, em resumo, é o interlocutor de Siebeck?

A função metodológica do texto também fica indeterminada. O leitor/ estudante provavelmente ficará confuso em relação a qual procedimento assumir diante do texto, pois não é indicada qualquer atividade que possa ajudar a compreendê-lo (talvez o momento histórico no Brasil ou o movimento hippie com seus símbolos de paz e amor, sexo, drogas e rock and roll, etc.) nem a estabelecer o diálogo deste com os demais do gênero informativo. O leitor/estudante não é sujeito localizado em um contexto cultural e histórico e pode se aproximar do texto de maneira similar aos exercícios automatizantes (apresentados no tópico 4) da perspectiva do 
estruturalismo. Andrade e Sá apontam ambigüidades conceituais como geradoras de representações estereotipadas no ensino comunicativo da língua estrangeira. Conforme as autoras:

Com efeito, assistimos freqüentemente a identificação simplista do ensino comunicativo das línguas com práticas de ensino funcional, cuja característica é muitas vezes apenas a substituição de itens programáticos tradicionais por inventários de actos de fala e enunciados mínimos actualizadores, simulando contextos verbais de utilização que, pela preocupação com a verosimilhança em sala de aula, se tornam extremamente redutores e artificiais do ponto de vista da comunicação e da própria relação pedagógica. (ANDRADE; SÁ, 1992, p. 19)

É relevante ressaltar que não existe na proposta metodológica do autorteam qualquer indicação de que o texto em questão é do gênero literário e que, portanto, o comprometimento com o factual - característica central dos textos informativos, gênero predominante na unidade - pode ser diluído em detrimento de uma elaboração criadora. Ao não considerar a experiência anterior do leitor/aluno e não apresentar elementos que possam lhe proporcionar a elaboração de uma mediação cultural/pedagógica apropriada, pode gerar uma profunda limitação na sua função de produção de sentido para o estudante. O estranho, ancorado na superficialidade, pode perpetuar uma visão monológica e abstrata, favorecendo leituras esquemáticas, adequadas a modelos formais pré-concebidos, inviabilizando o diálogo.

Concordamos com Faraco, que, ao apresentar a questão do dialogismo no texto "O dialogismo como chave de uma antropologia filosófica", no livro Diálogos com Bakhtin, percebe neste mais que uma categoria de análise, uma visão de mundo. Conforme o autor:

Preferimos nos incluir entre aqueles que entendem o dialogismo como uma Weltanschaaung, como um olhar compreensivo e abrangente do ser, do homem e de seu fazer cultural. Um olhar que não está mirando apenas aspectos desse real, mas pretende captá-lo numa perspectiva de globalidade; que pensa a cultura como um vasto e complexo universo semiótico de interações axiologicamente orientadas (...) (FARACO, 2001, p. 118). 


\section{REFERENCIAS}

AMMER, R. Das Deutschlandbild in den Lehrwerken für Deutsch als Fremdsprache Hrsg. von Dietrich Krusche und Harald Weinrich. München: iudicium verlag, 1988.

AUFDERSTRASSE, H. et al. Themen. Band. 1, 2. Munique: Max Hueber, 1982.

BAKHTIN, M. M. Estética da criação verbal. São Paulo: Martins Fontes, 1997. . Freudism. A marxist critique. New York: Academic Press, 1976. . Marxismo e Filosofia da Linguagem. São Paulo: Hucitec, 1979. 1981. . Problemas da poética de Dostoiévski. Rio de Janeiro: Forense-Universitária,

BELLER, M. Vorurteils- und Stereotyoenforschung - Interferenzen zwischen Literaturwissenschaft und Sozialpsychologie. In:WIERLACHER, A. Perspektiven und Verfahren interkultureller Germanistik. München, iudicium verlag, 1987.

CASTRO, G. Em busca de uma lingüística sociológica: contribuições para uma leitura de Bakhtin. Curitiba, 1993. Dissertação (Mestrado) - UFPR.

DORNBUSCH, C. S. Um cânone da literatura alemã nos trópicos. São Paulo, 1997.Tese (Doutorado) - USP/FFLCH.

EAGLETON, T. Teoria da Literatura. São Paulo: Martins Fontes,1994.

FARACO, C. A. O dialogismo como chave de uma antropologia filosófica. In: FARACO, C. A.; TEZZA, C.; CASTRO, G. de. Diálogos com Bakhtin. Curitiba: Ed. UFPR, 2001.

HINDERER, W. Das Phantom des Herrn Kanitverstan - Methodische Überlegungen zu einer Interkulturellen Literaturwissenschaft als Fremheitswissenschaft. In: WIERLACHER, A. (Org.). Kulturthema fremdheit. München: iudicium, 1993.

JANZEN, H. Mediação cultural, abordagem comunicativa e ensino de língua estrangeira: o conceito lingüístico de Bakhtin e os pressupostos da interculturalidade. São Paulo, 1998. Dissertação (Mestrado) - USP.

KOPP, G.; FRÖLICH, K. Ping Pong 2 - Dein Deutschbuch. München: Max Hueber Verlag, 1993.

NITSCHACK, H. Der Adoleszente als literarische Konstruktion. In: VERGLEICHENDE Literaturbetrachtungen. München: iudicium verlag, 1995.

SCHMIDT, H. W. Kulturspezifische Lektüren: Interkulturelle Hermeneutik oder Etnographie des Lesens? Stuttgart: Metzler, 1995.

SEVCENKO, N. Literatura como missão: tensões sociais e criação cultural na Primeira República. Brasiliense, 1999. 
WIERLACHER, A. (Ed.) Das Fremde und das Eigene. Prolegomena zu einer interkulturellen Germanistik. München: iudicium verlag, 1985.

. Perspektiven und Verfahren interkultureller Germanistik. München: iudicium verlag, 1987.

ZIMMERMANN, P. (Hg.) Interkulturelle Germanistik. Dialog der Kulturen auf Deutsch? Frankfurt am Main: Peter Lang, 1989.

Texto recebido em 22 jul. 2002

Texto aprovado em 26 ago. 2002 